\section{Selective Thallium Moult in Sheep}

Ir is known that sheep may be divided into two large groups according to the structure of their wool. The first group includes cultural races of sheep, the wool of which is homogeneous on the greater part of the body, that is, consists of identical fine curling wool fibres (merino and others). The second group includes a number of country unimproved races of sheep with coarse wool, which consists of fibres of different types, kemp and intermediary (mixedwoolled sheep).

I have already shown the possibility of stimulating in sheep a synchronous shedding of wool by treatment with a single dose of thallium compounds. This phenomenon was given the name of 'experimental thallium moult'1. In fine-woolled sheep this phenomenon has already been described ${ }^{2}$. I am now able to report the possibility of obtaining an analogous experimental thallium moult in mixedwoolled sheep.

Since mixed-woolled sheep are characterized by the heterogeneity of their fleece, their experimental moulting may a priori be thought of in at least two forms: (a) first case-a general shedding of the fleece ('general moult'); (b) the shedding of certain types only of wool fibres. We have obtained both these possible forms of experimental moulting in mixed-woolled sheep.

The experimental sheep belonged to the following races of mixed-wool sheep bred in the U.S.S.R. : the fat-rumped sheep of Casakhstan, the RussianWallach sheep of the North Caucasus, the chushkaKarakul of the Ukraine, the northern small-tailed sheep of the middle Russia, the fur Romanov sheep (Moscow region), the Armenian sheep, Balbas and Masekh. The experiments were carried out both at the Laboratory in Moscow and under farm conditions (Sovkhozes). The total number of mix-woolled sheep treated with different thallium compounds was 839 and that of untreated control ones 869 .

The shedding of certain types of wool fibres while other types of wool fibres remained unchanged was called 'selective or differential experimental moult'.

The course of the general experimental moult in mix-woolled sheep is identical with that in fine-woolled sheep described elsewhere.

The selective experimental moult is a peculiar reaction of the fleece that may be considered morphogenetic. Since fine wool and kemp differ in their structure, they may be expected to differ in their physiological properties as well. We supposed that the differences in the form and the structure of the various types of fibres should be accompanied by functional differences.

Engels's and Spencer's work on the connexion between form and function was the basic hypothesis for our study. These a priori theses of dialectical logic led us to study the influence of different doses of thallium acetate upon the heterogeneous fleece.

A number of experiments showed the different heights of the thallium threshold of the fine wool and the kemp fibres. With doses exceeding 12-13 mgm. the fat-rumped mix-woolled sheep shed both their kemp and their fine wool. With doses of $8 \cdot 5-9 \cdot 5 \mathrm{mgm}$. the root strength of kemp remains unchanged, while the fine fibres undergo a diminution of their root strength and consequently fall out. Hence the thallium threshold is approximately $11.5 \mathrm{mgm}$. for the kemp and about 9.0 mgm. for the fine fibres (stall keeping). This difference in the height of the thresholds for the kemp and the fine wool shedding is the theoretical basis for the realization of the selective moult of fine wool alone.

In a selective moult, the fine wool is always more or less mixed with a certain quantity of intermediate fibres or even of single broken kemp fibres. In the same way the kemp fibres which remain upon the body of the animal contain a certain admixture of fine wool fibres. The wool taken off as a result of a selective moult and containing chiefly fine wool fibres was given the name of 'fine fraction'. The wool which remains on the body of the animal was named 'coarse fraction'.

The effect of the selective moult in fat-rumped mixed-woolled sheep of Casakhstan is as follows : A normal 'original' wool cover proper to this race con. tains on an average 52.05 per cent of coarse and 47.95 per cent or even 31 per cent of fine wool fibres. The fine fraction contains $12 \cdot 6-14 \cdot 9$ per cent of coarse and $85 \cdot 1-87 \cdot 4$ per cent, in some cases $92-95 \cdot 8$ per cent, of fine fibres. The coarse fraction contains 80 $93 \cdot 1$ per cent of kemp and $6 \cdot 9-19 \cdot 8$ per cent of fine fibres.

Similar results are obtained with other races of sheep.

The experiments on selective moulting in sheep which we have carried out may be considered from both the theoretical and the practical points of view.

Selective moulting, as a peculiar morphogenetic reaction, is a proof of the possibility of a physiological distinction between morphologically different structures ("Morphologische und physiologische Erscheinungen, Form und Funktion bedingen einander wechselseitig" (Engels ${ }^{3}$ ) ).

Hence selective moulting is an excellent subject for the study of the part played by chemical agents in morphogenesis. It may, moreover, be considered as a method of analysis of living matter by means of the action of chemicals and pharmacons. These two methods demonstrate the theoretical importance of selective moulting in biology.

Selective moulting has obvious prospects of economically important industrial applications. The country mixed-woolled races are often very valuable because adapted to the climatic conditions and are utilized in many ways (for milk, flesh, fat, etc.). Their wool is of but small value because of its coarseness and heterogeneity. Nevertheless, the fine wool fibres contained in the fleece of sheep with heterogeneous wool does not greatly differ from the wool of fine-woolled sheep. Selective moulting makes it possible to obtain from coarse-woolled sheep with mixed wool, a fine wool approaching or even equalling merino as to wool quality. The only obstacle to a wide application of this method is the presence of certain harmful by-effects, which we shall describe elsewhere.

Wool Laboratory,

$$
\text { N. A. ILJIN. }
$$

Moscow.

Oct. 15.

${ }^{2}$ Iljin, N. A., Probl. Anim. Husbandry U.S.S.R., No. 3, 56 (1932); Rabbit Breeding U.S.S.R., No. 7, 12 (1932).

2 Iljin, N. A., J. Genet., 33, 305 (1936); C.R.Acad. Sciences U.S.S.R., 10, No. 86, 365 (1936). See also NATURE, 139, 104 (1937).

"Engels, F., "Naturdialektik" (Moscow, State Publishing Firm, 1925).

"Spencer, H., "Principles of Biology", 2 (1864-1867). 